\title{
Variability in the potential effects of climate change on phenology and on grape composition of Tempranillo in the Rioja DOCa (Spain)
}

\section{María Concepción Ramos ${ }^{1 *}$, Fernando Martínez de Toda ${ }^{2}$}

${ }^{1}$ Department of Environment and Soil Science-Agrotecnio. University of Lleida. Alcalde Rovira Roure, 191, 25198, Spain. cramos@macs.udl.es

${ }^{2}$ ICVV (Universidad de La Rioja, CSIC, Gobierno de La Rioja), c/ Madre de Dios, 51, 26006 Logroño, Spain. fernando.martinezdetoda@unirioja.es

*Corresponding author

\section{Abstract}

The objective of this research was to analyse the potential effect of climate change on phenology and berry composition of the variety Tempranillo cultivated in areas of the Rioja DOCa (Spain) with different climatic characteristics. Three zones were selected within the DOCa, which were located at elevations between 325 and $650 \mathrm{~m}$ a.s.l. Phenology and the evolution of berry composition during ripening was analysed for the period 2008-2018. This information included the dates of the phenological stages $\mathrm{H}$ (separated flowers), $\mathrm{M}$ (veraison) and maturity (based in a fixed value of the probable alcoholic degree (PVAD)) and as well as $\mathrm{pH}$, total acidity, malic acid, total anthocyanins, total polyphenols index and colour intensity, recorded in two plots at each location. The climatic conditions recorded during the period of study were evaluated from meteorological stations located close to the vineyards. The average predicted changes in temperature (maximum and minimum) and in precipitation, under two Representative Concentration Pathway (RCP) emission scenarios (RCP4.5 and RCP8.5) and simulated using an ensemble of 10 models were analysed by 2050 and 2070 for each zone. These data were obtained using the MarkSim $^{\text {тM }}$ DSSAT weather file generator. The relationship found at present between climate 
characteristics and the phenology and grape composition were considered in order to project the changes under climate change. The results indicated projected increase of temperature higher in the warmer than in the cooler area, and changes in average precipitation, which although being small will contribute to increase water deficits. The results predict that all evaluated phenological stages will suffer an advance, which will be higher for veraison and maturity than for the stage related to flowering. The advance of the stage $\mathrm{H}, \mathrm{M}$ and maturity for the three zones by 2050 could be up to 5,8 , and 12 days, respectively under the RCP4.5 emission trajectory, and up to 8,12 and 15, respectively under the RCP8.5 emission trajectory. The predicted advances indicate that the differences in timing that already exists between zones will be maintained or even increase, which will imply reaching maturity in the second half of August in the warmer area and in earlier September in the coolest one. Grape composition could also suffer changes, reaching the required PVAD earlier with a decoupling between anthocyanins and sugars and with lower acidity caused by the increase of temperatures.

Keywords: Acidity; Anthocyanins; Representative Concentration Pathway; Spatial variability; Temperature; Water deficit. 


\section{Introduction}

Permanent crops, and in particular vines are one of the crops that may suffer more negative impacts under climate change, due not only to changes in temperature but also due to water availability. Changes in timing of phenology events and in the length of the growing season are some of the first already observed effects during the last decades, which have further effects on grape quality and that could increase under climate change.

Climate plays an important role on berry composition, in addition to other factors such as soil characteristics, management and cultivar (van Leuwen, 2004; Jones and Storchmann, 2001; Storchmann, 2005; Makra et al. 2009; Tramontini et al., 2013; Cheng et al., 2014; Ashenfelter, 2018). Each variety can be cultivated in a given temperature range (Jones, 2012), and certain accumulated temperatures are required for grapevine growing onset (Bonada et al., 2015), but temperature also affects grapevine development and growth (Sadras and Moran, 2013; Webb et al., 2012). Thus, temperature may be considered as one of the main drivers of the evolution of the growing cycle and of the final maturity and berry composition (Sadras et al., 2007). Although some days with high temperatures may be beneficial during the ripening period, in excess may induce plant stress, a reduction of photosynthesis (Greer and Weedom, 2013). Under extreme temperatures, metabolic processes and sugar accumulation may be completely stopped, although an increase in sugar concentration may occur due to higher evaporative demand and a decrease in berry size and weight (Mira de Orduña, 2010). Finally, an impact on grape composition and flavor development may appear by alteration of secondary metabolites such as flavonoids, amino acids and carotenoids (Greer and Weedon, 2013; Ovadia et al., 2013).

The high spatial and temporal variability of climate, which mark differences between production zones, could be increased as a consequence of climate change. Studies carried out in different viticultural regions around the world evidence that climate change may have significant impacts on vine development. On one hand, the phenological phases may be affected. Most studies indicate an advance of the phenology phases (Duchêne and Schneider, 2005; Petrie and Sadras, 2008; Sadras and Soar, 2009; Bock et al., 2011; 
Webb et al., 2012; Ruml et al., 2015; Webb et al., 2007; Fraga et al., 2016) and in some cases a shortening of the cycle is projected (Tomasi et al., 2011; Jones et al., 2005; Ramos and Jones, 2019). On the other hand, grape composition could be also affected. The earlier harvesting means that it will take place at higher temperatures, which may have a negative impact on grape composition (Salazar Parra et al., 2010; Duchêne and Schneider, 2005; Sadras and Moran, 2013).

Another factor influencing grape development is water availability. In this respect, the amount and distribution of rainfall play an important role on water availability, which in addition is controlled by the soil capacity for water storage (Costantini et al., 2010; Ramos and Martínez de Toda, 2018; Ramos et al., 2020), and all together determines the water status with further influence on berry composition. The increase of temperatures may require higher water demands, and vines may suffer higher stress or during longer periods, in particular in rainfed vineyards. Water deficit can affect shoot growth, berry weight, berry anthocyanin and sugar content (van Leeuwen, et al., 2009) being the effect dependant on the level of stress. In this respect, Downey et al. (2006) indicates berry size reduction and changes in the ratio of skin/berry weight, which would affect phenolic concentrations, related to water deficits, and other authors have indicated an increase of anthocyanins and procianidin concentrations in berries when water deficits increased (Ojeda et al., 2002; Roby et al., 2004; Castellarin et al., 2007). As a result, the changes in temperature and in water availability may produce changes in vine physiology and the metabolism can be modified. An earlier maturity may occur, which may produce a decoupling between sugar and phenolic compounds and a decrease in acidity at maturatity in the berries. However, due to the intrinsic variability of climate, these effects of climate may vary among location, which allow exploring the best conditions to maintain grape production and quality.

In this research, the potential changes in phenology and in grape composition under future climate changes scenarios are evaluated, based on the vine response recorded at present under different climatic conditions and the potential changes in temperature and precipitation that climate change could imply under different scenarios. The research focus on the Tempranillo variety, which covers more than 50000 ha in the Rioja DOCa, representing about $80 \%$ of the vines cultivated in the region (Consejo Regulador 
Denominación de Origen Rioja, 2017) and it is one of the main producer regions of this variety in the world. The hypothesis is that the impacts of climate warming on phenology and on grape composition (sugar, acidity and anthocyanins ) could be different depending of the location of the vineyard in the landscape. The information extracted from this research could help to define strategies to maintain the grape quality of the area selecting the zones that could suffer lower impacts under potential climate change.

\section{Material and methods}

\subsection{Characteristics of the study area}

The study was carried out in the Rioja DOCa (Spain). This area is one of two viticultural areas of Spain with higher qualification (DOCa), with about 65000 ha of vines, mostly red varieties. The vines are cultivated from the terraces of the Ebro River to elevations up to about $700 \mathrm{~m}$ a.s.I. Within the Rioja DOCa, the Atlantic and Mediterranean influence, allows separating different areas, which are recognized as Rioja Alta (about 27000 ha) with Atlantic influence, Rioja Alavesa (about 13000 ha) with intermediate climatic influence and Rioja Oriental (about 24000 ha), with Mediterranean influence.

The main soil type in the Rioja DO vineyards are classified as: Typical Calcixerepts, which are soils with a calcareous horizon enriched by an accumulation of carbonates; Calcic Haploxeralfs, Calcic Palexeralfs and Petrocalcic Palexeral, Inceptisols and Alfisols, which display an argillic horizon, enriched in the clay fraction, and a calcic horizon below this, that appears to be extremely cemented (García-Escudero, 2018). The soils of Rioja Alta and Rioja Alavesa usually contain clay-lime-stone materials and clay-ferrous materials, while in Rioja Oriental alluvial soils with the presence of gravel, sand, silt and clay are common.

Three zones with different climatic characteristics within the Rioja DOCa were selected for this research. Two of them were in Rioja Alta (denoted as RA1 and RA2), which were located at different elevation, and the third zone was in Rioja Oriental (RO), which is an area located at lower elevation and with warmer temperatures. In each zone, information related to phenology and grape composition of two plots was 
evaluated. The plots in RA1 were located in the municipalities of Haro and Cenicero at $465,450 \mathrm{~m}$ a.s.l., respectively. The plots in RA2 were located in Sotés and Alesanco at 635 and $650 \mathrm{~m}$ a.s.l., respectively, and the plots in RO were located in the municipalities of Alfaro and Aldeanueva de Ebro, which were located at 325 and $396 \mathrm{~m}$ a.s.l., respectively (Fig. 1). Vines were planted between 1993 and 1999; they were bush trained and cultivated under rainfed conditions, with 3,000 to 3,500 vines/ha.

Soil characteristics of each plot were obtained from the European Soil data base (ESDAC) (esdac.jrc.ec.europa.eu, European Commission, Joint Research Centre). The information included soil organic carbon, soil particle distribution (clay, sand, silt and coarse elements) and soil water retention corresponding to field capacity and wilting point. The soil characteristics of the studied plots are shown in Table 1. The soils of the studied plots have organic carbon contents that varied between 0.60 and 1.53\%; clay contents that range between 21.1 and $29.7 \%$; silt contents that range between 38.4 and $49.6 \%$ and sand contents that ranged between 27.9 and $39.4 \%$. The water retention corresponding to field capacity ranged between 25.2 and $27.9 \%$ and that for the wilting point ranged between 15.3 and $17.1 \%$. Considering an average soil depth of $0.9 \mathrm{~m}$, the maximum water holding capacity of the soils ranged between 145 and 176mm (estimated using the methodology proposed by Saxton et al., 1986).

\subsection{Vine phenology and grape composition}

The response of the vines in each zone related to phenology and grape composition were evaluated for the period 2008-2018. The information was provided by the Consejo Regulador Rioja DOCa (personal communication). For each zone, the dates of the phenological stages $\mathrm{H}$ (flowers separated) and $\mathrm{M}$ (veraiosn) defined according to Baillod and Bagiollini (1993), whose dates were available for two plots in each zone for the period 2008-2018, were analysed. Maturity was defined based on the date in which a given probable PVAD was reached. In that case PVAD $=13^{\circ}$ was considered. In order to stablish the date of budbreak at present, additional information was obtained from previous works carried out in the area of study (Pérez, 2016; Martinez de Toda and Balda, 2015; Zheng et al., 2017). The information did not cover all years, but it allowed stablish the average date for the starting point of the growth season in each zone. 
Grape composition at ripening (when PVAD=13 was reached), including $\mathrm{pH}$, total acidity (AcT), malic acid (AcM), total anthocyanins (AntT), total polyphenols index(TPI), and colour intensity (CI) was evaluated for the period under study (2008-2018). All analysis were done following the methods recommended by the OIV (OIV, 2012).

\subsection{Climate data}

The climatic conditions for the analysed period were recorded in meteorological stations located near the analysed plots. Data from Haro, Uruñuela, Villar de Torre, Alfaro and Aldeanueva de Ebro (Fig. 1), which belongs to La Rioja Government were analysed. The information included daily maximum and minimum temperatures, precipitation and potential evapotranspiration (ETo). From this information, the average temperature and precipitation referred to the growing season (GS) $\left(15^{\text {st }}\right.$ April-15 ${ }^{\text {th }}$ Oct) as well as the accumulated degree days (base $10^{\circ} \mathrm{C}$ and base $0^{\circ} \mathrm{C}$ ) were calculated. In addition, crop evapotranspiration was estimated taking into account the crop coefficients proposed by Allen et al. (1998). Water deficits for the whole growing season (GS) and for periods between phenological stages (budbreak to bloom (BB-BL); bloom to veraison-BL-V; veraison to maturity (V-M)) were then quantified as accumulated precipitation minus crop evapotranspiration recorded in each period. The average dates of budbreak, bloom, veraison and maturity recorded during the analysied period were considerd to define the diffenret periods between phenological stages.

The present climatic conditions were compared with temperature and precipitation, predicted under two emission scenarios (RCP4.5 and RCP8.5) by 2050 and 2070. The data were simulated using the MarkSim ${ }^{\mathrm{TM}}$ DSSAT weather file generator. This application works with a 30 arc-second climate surface derived from WorldClim, http://gismap.ciat.cgiar.org/MarkSimGCM/). For each zone, daily maximum and minimum temperatures and precipitation simulated using 10 models (BCC_CSMI_1M; CSIRO_MRk3-6-0; GFDL_ESM2M; GISS_E2H; HADGEM_ES; IPSL_CMJA_MR; MIROC_ESM_CHEM; MIROC5; MRI_CGCM3; NorESMI_M, http://gismap.ciat.cgiar.org/ MarkSimGCM/docs/doc.html) were downloaded for the locations from which the information of the phenology and composition was available. As the differences 
in the predictions between the two locations were not significant, the final results were expressed for each zone as the average projected changes for each location.

Based on those projections of the climate variables, the potential changes in vine response were evaluated, both in phenology and in grape quality. In order to analyse and predict phenology, different threshold temperatures have been proposed in the calculation of the thermal requirements (Parker et al., 2011; Molitor et al., 2014; Real et al., 2015; Ramos, 2017; Zapata et al., 2017, among others). In this research, taking into account the available information referred to phenological dates, the model proposed by Parker et al. (2011), accumulating temperature from DOY $=60$ and using $\mathrm{Tb}=0^{\circ} \mathrm{C}$, was used to analyse heat requirements for flowering and veraison stages. For maturity, the same methodology was applied, and also accumulating temperatures from DOY=91 and using $\mathrm{Tb}=0{ }^{\circ} \mathrm{C}$ (Parker et al., 2019). An additional approach was applied, which consists of accumulating temperature from veraison to maturity, using a base temperature estimated through an iterative process until reaching the temperature that minimised the standard deviation for GDD, as described in Ramos (2017). The optimization was done using the Generalized Reduced Gradient (GRG) in the SOLVER tool (Microsoft Office Excel 2010). If the mean daily temperature ( $T \mathrm{i})$ was $<\mathrm{T} b$ then $T i=T b$ and no GDD were accumulated and a maximum stress heat threshold of $22{ }^{\circ} \mathrm{C}$ was considered, which is in agreement with the maximum warm threshold proposed by Molitor et al. (2014). The fit of the predicted dates was analysed for each plot using the root mean square (RMSE) calculated as indicated in Eq.1

$R M S E=\sqrt{\frac{\sum_{1}^{n}(D O Y S-D O Y o)^{2}}{n}}$

In order to analyse the effect of climate change on grape composition, each analysed parameter was related to temperature variables relative to the growing season (mean, maximum and minimum growing season tempertures (TmGS, TmaxGS and TminGS) and accummulated GDD, and precipitation, relative to the growing season and periods between phenological stages (PGS, PBB-BL, PBL-V, PV-M), using a stepwise multiple regression analysis. The analysis was done separately for each zone. The Statgraphics package was used for the statistical analysis. 


\section{Results}

\subsection{Climatic characteristics of the studied zones}

The information recorded during the analysed years (2008-2018), which presented high variability in the climatic conditions, showed TmGS ranging between 14.7 and $18.0{ }^{\circ} \mathrm{C}$ in Rioja Alta, with differences between the zones located at different elevation, and between 17.0 and $19.4{ }^{\circ} \mathrm{C}$ in Rioja Oriental. The TmaxGS varied between 20.8 and $26.1^{\circ} \mathrm{C}$ in Rioja Alta and between 24.2 and $27.2^{\circ} \mathrm{C}$ in Rioja Oriental, while the TminGS ranged between 9.4 and $12.0^{\circ} \mathrm{C}$ in Rioja Alta and between 11.1 and $13.0{ }^{\circ} \mathrm{C}$ in Rioja Oriental (Fig. 2).

Regarding precipitation, annual precipitation ranged between 345 and $714 \mathrm{~mm}$ in Rioja Alta and between 310 and $638 \mathrm{~mm}$ in Rioja Oriental, although higher variability from year to year existed. Precipitation during the growing season tends to be scarce, ranging between about 100 and $456 \mathrm{~mm}$ in Rioja Alta and between 120 and $353 \mathrm{~mm}$ in Rioja Oriental, and irregularly distributed throughout the cycle (Fig. 2). This means important water deficits during the growing cycle, in particular in summer. Despite the variation between the three analysed zones, the precipitation recorded during the growing season in the three zones during the period of analysis did not present significant differences.

3.2. Vine response during ripening in the three zones under different climatic conditions

3.2.1. Phenological dates and thermal requirements

During the analysed period, differences in phenology were observed among years with different climatic characteristics and also among the three zones considered in this research. The date at which the $\mathrm{H}$ stage (flowers separated) was reached ranged between $12^{\text {th }}$ May and $2^{\text {nd }}$ June in RO, between $23^{\text {rd }}$ May and $8^{\text {th }}$ June in RA1, and between $26^{\text {th }}$ May and $14^{\text {th }}$ June in RA2. The differences between RA1 and RA2 in the average phenological date of the stage $\mathrm{H}$ were of 4 days while in $\mathrm{RO}$ that stage was reached, on average, 6 days before than in RA1. The later dates for stage $\mathrm{H}$ were recorded in the three zones in 2013, which 
was a very wettest and coolest years in the series analysed. On the contrary, the earlier dates were recorded in 2009, which was one of the driest and warmest years on the series analysed.

For the stage $\mathrm{M}$ (veraison), the date at which was reached ranged between $23^{\text {rd }}$ Jul and $12^{\text {th }} \mathrm{Ago}$ in RO, between $29^{\text {th }} \mathrm{Jul}$ and $27^{\text {th }}$ Ago in RA1 and between $4^{\text {th }}$ Ago and $28^{\text {th }}$ Ago in RA2. The differences between RA1 and RA2 in the average phenological date of the stage $M$ were of 5 days while in RO that stage was reached, on average, 9 days before than in RA1. The earliest dates were recorded in 2015, in which the precipitation recorded during the growing period was quite scarce, while the later dates for stage $M$ were recorded in the three zones in 2008 and in 2013, which were very wet years. The average dates of the analysed phenolgical events are shown in Table2. The duration of the period between flowers separated and veraison ranged between 74 and 80 days, respectively in Rioja Oriental and RA2, while the period between veraison and maturity ranged between 41 and 46 days, respectively in the same zones.

The thermal requirements to reach these phenological stages, calculated from DOY=60 and using a Tbase $=0$, as proposed by Parker et al. (2011) to predict flowering and veraison were: $962 \pm 37,994 \pm 56$ and $906 \pm 63$ GDD for stage $H$ (flowers separated) and $2583 \pm 134,2512 \pm 81,2342 \pm 72$ GDD for stage M (veraison), respectively in RO, RA1 and RA2. To reach the threshold of $13^{\circ}$ for PVAD, the thermal requirements, calculated using the same approach, were $3214 \pm 325,3365 \pm 159$ and $3259 \pm 132$ GDD, respectively in RO, RA1 and RA2. The differences between the observed and modelled dates using this approach was estimated for each zone, with RMSE that ranged between 3.9 and 6 for the stage $\mathrm{H}$, between 3.6 and 6.4 for stage $M$ and between 9.7 and 11.3 for maturity. Using heat accumulation from $\mathrm{DOY}=91$, the fit was worst, with RMSE values that ranged between 12 and 13.5. Using the approach, Tb estimated for the period between veraison and maturity ranged between 13 and $13.4^{\circ} \mathrm{C}$. Similar RMSE were observed when predicted and observed dates were compared, which ranged between 11.2 and 11.7. As this approach did not improve the results, the same method was used to predict all three phenological dates under the different climate change scenarios.

3.2.2. Grape composition related to climatic characteristics 
The average values of the grape composition recorded during the period under study in each zone are presented in Table 3. Despite the reduced number of plots included in the analysis, there were some differences among areas. Nevertheless, it is neccesary to take into account that high differences exist among years (warm vs. cold, and wet vs. dry season) (Martínez de Toda and Ramos (2019), which could be even higher than the differences of the average among zones.

The analysis of the influence of different temperature variables (TmaxGS, TmGS, TminGS) on acidity and on the polyphenol contents evaluated using a regression analysis, showed that TmaxGS was the variable that presented significant influence. Figure 3 shows the variation of total acidity, malic acid, anthocyanin concentration and TPI with TmaxGS during the period under study (2008-2018) in the three analysed areas. The results showed a decrease of total acidity of $0.33,0.42$ and $0.73 \mathrm{~g} \mathrm{~L}^{-1}$, respectively in RO, RA1 and RA2 per an increase of $1^{\circ} \mathrm{C}$ in the TmaxGS. Similarly, the malic acid concentration decreased $0.63,0.75$ and $0.4 \mathrm{~g} \mathrm{~L}^{-1}$, respectively in RO, RA1 and RA2 per an increase of $1^{\circ} \mathrm{C}$ in TMaxGSduring the growing season. Regarding anthocyanin concentrations, it was observed that they decreased 36 and $20 \mathrm{~g} \mathrm{~L}^{-1}$ for an increase of $1^{\circ} \mathrm{C}$ in TmaxGS, respectively in RA1 and RA2. In RO, however, the best relationship was found with the accumulated GDD (accummulated from $15^{\text {st }}$ April), showing a decrease of concentration when the thermal condition reached at maturity was higher. A decrease of about $0.5 \mathrm{mg} \mathrm{L}^{-1}$ in the anthocyanin concentration for an increase of 1 GDD was observed. For polyphenols, however, the relationship between the TPI and temperature showed an increase that ranged between 1.47 units in RA1 and 3.2 units in RO, per an increase of $1^{\circ} \mathrm{C}$ in the TmaxGS. In addition, it was observed that colour may be also affected as colour intensity decreases with TmaxGS 0.6 and 0.75 units per $1^{\circ} \mathrm{C}$ increase of the TmaxGS, respectively in RA1 and in RA2

On the other hand, anthocyanin concentrations were also conditioned by water deficits. It was observed than in all three zones, anthocyanin concentrations increased with water deficits. The increase was of about 32.7, 18 y $13 \mathrm{~g} \mathrm{~L}^{-1}$ respectively in RA2, RO and RA1, for $100 \mathrm{~mm}$ water deficit. However, due to water reserves during the dormant period and accummulated water during the fist crop stage, the main water 
deficits usually start to appear after bloom and it was observed that accumulated water deficits recorded in the periods between bloom and veraison and between veraison and maturity showed in fact higher impacts (an increase between 25.1 and $35.8 \mathrm{mgL}^{-1}$ per $100 \mathrm{~mm}$ of increasing deficit in the period bloom to veraison and an increase between 35.7 and $51.8 \mathrm{mgL}^{-1}$ per $100 \mathrm{~mm}$ of increasing deficit in the period veraison to maturity. Figure 4 shows the influence of water deficits in these both periods on anthocyanin concentrations recorded during the studied years in the analysed zones.

3.3. Climate projections under the RCP4.5 and RCP 8.5 scenarios and their impacts on vine development and grape composition

The projected changes for 2050 and 2070 (average obtained with the 10 models), under the RCP4.5 and RCP8.5 emission scenarios, which were obtained for each location, are shown in Table 4 . The values for precipitation represent the ratio between predicted values and the ones and recorded during the reference period (1970-2000), while the values for Tmax and Tmin show the predicted increase in degrees.According to the predictions obtained with the models, despite the irrgularities in rainfall distribution, a decrease of precipitation of about $20 \%$ could be expected under the RCP 4.5 scenario and about $30 \%$ uner the RCP8.5 scenario. However, the predicted decrese is not uniforme along the growing cycle, being higher in the months correponding to the period bloom to veriason than in the period veraison to harvest. In the first mentioned period the decrease could be of about $30 \%$ by 2050 under RCP4.5 in RA1 and in RO, and about $20 \%$ in RA2. Under the RCP8.5 scenario, the decrease could be of up to $40 \%$ in $\mathrm{RO}$ and $30 \%$ in RA. Howerer, the decrease during ripening coud be of about $20 \%$ in RA1 and in RO, and about $10 \%$ in RA2.

Regarding temperature, for both Tmax and Tmin, an increase is predicted, which could be up to $3.2^{\circ} \mathrm{C}$ in summer months in the warmer zone, and about $2.4^{\circ} \mathrm{C}$ in the coolest analysed zone. Similarly, Tmin is predicted to increase between 2.3 and $2.5^{\circ} \mathrm{C}$ in summer and between 1.2 and $1.4^{\circ} \mathrm{C}$ in winter. The average increase in Tmax during the growing season may range between 2.4 and $2.5^{\circ} \mathrm{C}$ while Tmin may increase between 1.75 and $1.85^{\circ} \mathrm{C}$, respectively in the coolest and warmest areas. Thus, the increase in Tmax during 
the growing season may be of about $2.4^{\circ} \mathrm{C}$ in $\mathrm{RA} 2,3.0^{\circ} \mathrm{C}$ in $\mathrm{RA} 1$ and of about $2.5^{\circ} \mathrm{C}$ in $\mathrm{RO}$, while Tmin may increase $1.5,2.5$ and $2^{\circ} \mathrm{C}$, respectively in each zone.

Under the RCP8.5 emission scenario, the changes in precipitation may be even higher than those commented for the scenario RCP4.5 in summer (up to $40 \%$ lower) but smaller in the winter months (December and January) (Table 4). Maximum temperatures are projected to increase up to $4^{\circ} \mathrm{C}$ in summer months in $\mathrm{RO}$ and up to $3.9^{\circ} \mathrm{C}$ in RA, while minimum temperatures could increase up to $3^{\circ} \mathrm{C}$ in summer and about $1.8^{\circ} \mathrm{C}$ in winter. The average increase in Tmax during the growing season may range between 3 and $3.3^{\circ} \mathrm{C}$ and $\operatorname{Tmin}$ might increase between 2.5 and $2.8^{\circ} \mathrm{C}$, respectively in the coolest and the warmest areas.

Consideirng the projections of temperature and in solar radiation, and for a average characteristic amount and distribution for each area, an estimation of ETo was done and then crop evapotranspiration was also estimated. Taking into account the changes in precipitaiton and in evapotranspiration, the changes in deficits for the periods budbreak to bloom, bloom to veraison and veraison to maturuty were evaluated. The values are shown in Table 5.

\subsubsection{Projected changes in phenology}

The projected changes in phenology were evaluated for each analysed zone taking into account the average thermal requirements observed for the Tempranillo variety and the projected changes in temperature. The results are shown in Table 6. The advance is projected to be higher for veraison than for the earlier analysed stage (flowers separated). This means that under the RCP4.5 scenario, the stage $\mathrm{H}$ (flowers separated) would occur in mid-May in RO and in the first third part of May in RA, while veraison would occur at the end of July in RO and at the beginning of August in RA. These projections are in agreement with the differences observed during the period of analysis between the warmest years and the average. Thus, the stage $\mathrm{H}$ in 2009 occurred 6 days before the average in zone RA1, 4 days before in RA2 and 7 days before in RO. Similarly, veraison occurred 10 days before the average in RA1, 12 days before the average in RA2 and 7 days before in RO. 
Following the same approach of considering the heat requirements at which maturity was reached, it was found that under the analysed scenarios, maturity can take place, by 2070 , up to 12 days before in RO under the emission scenario RCP4.5 and up to 22 days before under the emission scenario RCP8.5. For the zones in RA, the advance is projected to be 12 and 14 days under the RCP4.5 scenario and up to 21 and 21 days under the RCP8.5 scenario, respectively in RA1 and RA2 (Table 6). This means that maturity would be reached at the end of August in RO, and in mid-September in RA by 2050 under the scenario RCP4.5 and much earlier under the scenario RCP8.5.

The projected changes in the phenological dates suggest also changes in the duration of the periods between phenological events. A shortening of both analysed periods (period between the stage $\mathrm{H}$ (flowers separated) and the stage $M$ (veraison) and between the stage $M$ and maturity) may result, which according to the predicted results would be higher in last period (of about 4 days in RA and between 3 and 6 days in RO, depending on the scenario). The projected shortening of both periods are shown in Table6.

\subsubsection{Potential changes in grape composition}

The relationship between the grape composition at maturity and temperature, can give an idea of their potential changes under climate change. The predicted changes in the analysed grape variables are shown in Table 7. The predicted values imply changes in total acidity of up to $0.9,1.1$ and $1.2 \mathrm{~g} \mathrm{~L}^{-1}$ could be recorded by 2050 under the RCP4.5 scenario and up to $1.2,1.4$ and $2.4 \mathrm{gL}^{-1}$ under the RCP 8.5 , respectively in RO, RA1 and RA2.

The observed values in years with differences in TmaxGS are in agreement with these results. For example, the acidity values in RA2 in 2013, 2018 and 2017 were 9.1, 6.8 and $4.7 \mathrm{~g} \mathrm{~L}^{-1}$, when TmaxGS in those years were $20.8,22.4$ and $23.8^{\circ} \mathrm{C}$ respectively. Similarly, total acidity for the same years in RA1 were $8.4,6.1$ and $3.8 \mathrm{~g} \mathrm{~L}^{-1}$, being $\operatorname{TmaxGS} 23.0,24.9$ and $26.3^{\circ} \mathrm{C}$, respectively. However, the differences for the same years in $\mathrm{RO}$ were smaller $\left(6.2,5.2\right.$ and $4.9 \mathrm{~g} \mathrm{~L}^{-1}$ when TmaxGS was $24.6,26.3$ and $\left.27.2^{\circ} \mathrm{C}\right)$. Similar differences were also found for the malic acid. The concentrations at ripening were 5.0, 4.2 and $4 \mathrm{~g} \mathrm{~L}^{-1}$, respectively 
in the same years in RA1, and4.5, 2.61 and $2.5 \mathrm{~g} \mathrm{~L}^{-1}$ in RO. Malic acid can also experience high changes (Table 7), of up to 2 and $2.6 \mathrm{gL}^{-1}$ by 2050 in RA1, respectively, under the RCP4.5 and RCP8.5 scenarios, being the projected changes smaller in RO.

For anthocyanins, the predicted changes for RA are shown in Table 7 (for RO, no significant correlations with TmaGS were found). Taking into account the predicted increase in temperature, anthocyanin concentrations could decrease, being higher the decrease in RA1 than in RA2, Tthe changes by 2050 could be up to $97 \mathrm{gL}^{-1}$ and $122 \mathrm{mgL}^{-1}$ in RA1 and 32 and $66 \mathrm{mgL}^{-1}$ in RA2, respectively under RCP4.5 and RCP8.5. The relationship observed in RO between anthocynins and the accumulated GDD points out in the same direction. Although in this case the change with temperature cannot be quantified, maturity will be reached before, which may produce an imbalance situation with other grape parameters. Based on the relationship between TPI and temperature, an increase in TPI of up to 8.2 units in RO and up to 31 units in RA2 could be expected under the emission scenario RCP4.5, by 2050 . Colour intensity also may decrease up to 2 units in RO and up to 3.6 units in RA2.

These changes in anthocyanin concentrations, total polyphenlos and colour could be also affected by water deficits. Water deficits in some periods within the growing cycle produce an increase of anthocynins and polyphenols. However, the prediction of the effect of water deficits on grape parameters implies to take into acocunt not only changes in precipitation but also changes in temperature and radiation as they influence evapotranspiration. The increase of temperature may produce higher evapotranspiration and in addition the prediction under the different emission scenarios may give rise to lower water inputs (Table 4). For each zone, ETo was stimated for the climatic conditions predicted by 2050 and 2070 under both scenarios (RCP4.5 and RCP8.5) vs. the present conditions, considering temperature, precipitation and radiation changes. The results showed that the main differences in water deficits could be due to the water inputs, that is due to changes in precipitation. The changes imply an increase in water deficits by 2050 of up to 112 and $144 \mathrm{~mm}$ in the period bloom to veriason, and up to 108 and $135 \mathrm{~mm}$ in the period veraison to maturity, respectively under the RCP4.5 and RCP8.5 in RA1. For RA2, the increase in water defcits could be up to 98 and $112 \mathrm{~mm}$ in the period bloom to veriason, and up and 13 and $43 \mathrm{~mm}$ in the 
period veraison to maturity, respectively under the RCP4.5 and RCP8.5 scenarios. For RO, the incerase in water defiicts could be up to 57 and $80 \mathrm{~mm}$ in the period bloom to veriason, and up to 68 and $96 \mathrm{~mm}$ in the period veraison to maturity, respectively under the RCP4.5 and RCP8.5 in RA1. The increases in anthocyanin concentrations under the different scenarios, for the three analysed areasm, are presented in Table 7. The increase may be higher in RA1 than in RA2 and in RO.

\section{Discussion}

\subsection{Projected changes in phenology}

The first effect of the increasing temperatures projected under climate change will be the advance in the phenological timing. In this research, it was confirmed that phenology of the earlier stages will suffer less advance than the stages that occur under higher temperature. Thus, veraison and maturity are projected to be advanced more than flowering.

The projected advance in phenology with increasing temperatures agrees with results found in different viticultural areas around the world for different varieties (Duchêne and Schneider, 2005; Sadras and Soar, 2009; Bock et al., 2011; Webb et al., 2011; Webb et al., 2012; Ruml et al., 2015, van Leeuwen and Darriet, 2016, among others). In the present research the analysis was done considering the average temperature for the whole growing season being TmaxGS the variable that had higher influence. Koufos et al. (2014) also linked the earlier harvest to changes in maximum and minimum temperatures. Other authors had indicated the influence of maximum temperatures recorded in specific periods. Thus, Bock et al. (2011) found that flowering was influenced by the maximum temperature of the preceding months (April to June) and veraison was dependent on temperature in later time periods (May to July). Malheiro et al. (2013) also indicated relationships between the main phenophases and temperature of the preceding months. 
The projected changes in phenology were also in line with the prediction done in other regions. Pieri (2010) projected advances higher than 10 days for flowering and harvest by 2050 and near twice by 2070 for Merlot in different areas in France. Fraga et al. (2016) indicated that bloom is expected to advance between 2 and 6 days and veraison between 6 and 14 days. Webb et al. (2007) found that the Cabernet Sauvignon harvest could be 45 days earlier by 2050 under the warmer scenario. Ramos et al. (2018), projected for the same variety in other Spanish vititultural area, an advance of bloom of about 6 days by 2050 and up to 7.9 days by 2070, and an advance of veraison of about 13 and 18 days, respectively for 2050 and 2070. Ruml et al. (2015) indicates average advances in the beginning of bloom, veraison and harvest of $3.1,5.2$ and 7.4 days for an increase of $1^{\circ} \mathrm{C}$.

The analysis of the three areas with different climatic conditions showed that the predicted advances did not differ very much between zones. However, within the RA zone, the changes could be slightly higher in RA2 than in RA1 for the areas where the analysed plots were located, while in RO, the changes were of the same order of magnitude than in RA2 or slightly higher. By 2050 and under the emission scenario RCP4.5, the advance of the stage $\mathrm{H}$, differed 2 days between RA1 and RA2 and also 2 days between RO and RA2. For veraison, the advances seem to be quite similar in both analysed areas of RA and slightly smaller than in RO. For maturity, the differences were smaller also of about 2 days between RA1 and RA2, but similar to that in RO. Under the scenario RCP8.5, the differences in the predicted advance were smaller, with stage $\mathrm{H}$ advance of about 7 and 10 days and up to 8 and 12 days in RA2 and in RO, repectively by 2050 and 2070. Similarly the differneces between zones in the predicted advance for veraison and maturity were one or two days . Caffarra and Eccell (2011), pointed out a more pronounced phenological response at higher elevations However, Ramos and Jones (2019) found higher advance in warmer areas indicating differences in the prediction of phenology of Cabernet Sauvignon cultivated in two areas with differences in climatic conditions higher than 2 days for veraison under the emission scenario RCP4.5 and near 5 days under the scenario RCP8.5. The response may be affected by additional local factors, and additional research should be done by comparing the response at different zones within each specific area. The small differences in the advances in phenology will made that in the future, similar of slightly 
higher differences will exist in the phenological dates between RO and RA, which will mean ripening very early in mid-August or in the second half of August in in RO (between $11^{\text {th }}$ and $21^{\text {st }}$ Ago), and in the first third of September in RA (between $5^{\text {th }}$ and $14^{\text {th }}$ Sep.), under the most unfavourable climate change scenario.

In relation to these projected advances in the ripening of the grape, it seems interesting to study and develop new viticultural techniques of canopy management with the aim of delaying ripening so that, under the future climatic conditions, the grapes ripen under similar temperatures to the current ones. Various management techniques have been proposed, in Rioja and with "Tempranillo" variety, for delaying grape ripening, such as late winter pruning (Zheng et al., 2017a), shoot trimming (Martínez de Toda et al., 2014; Zheng et al., 2017b) and minimal pruning (Zheng et al., 2017c). Each of these techniques allows delaying the ripening of the grape between 15 and 20 days. Another technique capable of delaying ripening up to two months, and also studied in Rioja and in the Tempranillo variety, is the forcing vine regrowth (Martínez de Toda et al., 2019).

\subsection{Projected changes in grape quality}

The variation of acidity with increasing temperature agrees with the results found by other authors, who indicate that grape berries from a hot environment are likely to have lower acidity than berries from a cool environment (Sadras and Moran, 2012). In the same direction, Torres et al (2017) indicated that elevated temperture decreases tartaric acid in berries. During the last decades, a decrease in total acidity has been already found in some areas (Duchêne and Schneider, 2005; Vršič and Vodovnik, 2012; van Leeuwen and Darriet, 2016, among others) which has been associated to an increase in temperature and also to increasing $\mathrm{CO}_{2}$ concentrations, and radiation and changes in management techniques (van Leeuwen and Darriet, 2016). Thus, it is expected that under an increase of temperature associated to climate change a decrease in acidity may occur. The relationship between the grape composition at maturity and temperature, can give an idea of their potential changes under climate change. Taking into account the predicted changes in Tmax commented before, total acidity could decrease between 0.9 and 
$1.2 \mathrm{~g} \mathrm{~L}^{-1}$ by 2050 under the scenario RCP4.5 and up to $2.4 \mathrm{~g} \mathrm{~L}^{-1}$ under the RCP8.5 emission scenario (Table 7). The results agree with the predictions made for other areas and varieties. Neuman and Matzarakis (2014) in Germany projected a decrease in titratable acidity between 0.5 and $2 \mathrm{~g} \mathrm{~L}^{-1}$ from one 30-year period to the next under the A1B and A2 emission scenarios.Barnuud et al., (2014), in an analysis of potential effects of climate change in different varieties in Australia, found a projected titratable acidity decline in different zones, with larger reduction in the present days warmer, indicating a reduction of $15 \%$ for Shiraz and $12 \%$ for Cabernet Sauvignon by 2070 . However, in the study case, the predictions showed higher decrease in total acidity in RA2 than in RA1 and with the lowest changes in RO, but the predicted changes in malic acid were lower in RA2 than in other two analysed zones (Table 7).

Regarding the anthocyanin concentrations, the projected decrease of concentrations with increasing temperatures is in line with the results found by other authors. Barnuud et al. (2014) projected in Australia that anthocyanin accumulation will be reduced under climate change depending on the projected scenario, zone and the cultivar. These authors indicated that median anthocyanins concentrations are projected to decrease, by up to $12 \%$ by 2030 and up to $33 \%$ and 2070 in the northern wine regions, while in the southern wine regions the reductions could be smaller (up to 2 and $18 \%$ lower, respectively, in the same time periods). Regarding the effect of increasing temperature on anthocyanin Mori et al. (2007) indicated that high temperature increases anthocyanin degradation in grape skin.

The results observed in this research also confirmed the need of combining the effect of different environmental factors, because the response may be different (Conradie et al., 2002) and it can affect the metabolic pathways of some compounds (Deluc et al., 2009). The effect of different degrees of water deficit and the time that it occurs on phenolic compounds has been analysed by different authors (Ojeda et al., 2002; Hochberg et al, 2015; Cáceres-Mella et al.; 2017). Water deficits may increase anthocyanins and total phenolic compounds, mainly due to a berry size reduction and biosynthesis (Ojeda et al., 2002), although the different compounds may be affected in different ways depending the cultivars and rootstocks (Ojeda, et al., 2002; Berdeja et al., 2014; Hochberg et al., 2015). Castellarin et al (2007) and Salazar et al. (2010) found differences in anthocyanin extractability under elevated CO2 and temperature 
depending on the irrigation rates. While under partial irrigation, the amount of anthocyanins extracted increased over the maximum possible under current $\mathrm{CO} 2$ and temperature conditions, in absence of drought total anthocyanins concentrations decreased. In this research the anthocyanin concentrations were affected by both, temperature and water deficit, decreasing with increasing temperature accumulation during ripening and increasing when water deficit increased in the period between bloom and veraison, with differences in the changes between RO and RA. Thus, changes in temperature and in water deficits can affect polyphenol contents: increasing temperatures produce a decrease in anthocyanins, but increasing water deficits due to decreasing precipitation and increasing evapotranspiration favour the increase of anthocyanin concentrations. The predicted changes in precipitation and evapotranspiration may give rise to higher water deficits, which produce an opposite effect on anthocyanin concentrations to those of tempreture increase. In RA2, the increase due to water deficits could balance the decrease due to increasing temperature under RCP4.5 scenario, but the balance would be negative under the RCP8.5 scenario. However, in RA1 the decrease in anthocyanin concentrations due to increasing temperatures can be higher than the increase due to increasing water deficits, which will produce net reduction of anthocyanins. Nevertheless, it must be taken into account that the effective available water for the crop is influenced by soil properties under similar climatic conditions, which may condition the timing in which water deficit started to be critic and affected grape composition (Ramos et al., 2020). These authors indicate that not irrigated vines located in RA1 zone suffered stress equivalent to $50 \%$ of the maximum available water capacity only few weeks after reaching the stage $\mathrm{H}$, and severe stress (equivalent to $20 \%$ of water available capacity) at veraison.

Similarly, the IPT could increase due to water deficits up to 5.4, 3.1 and 2.1 units respectively in RA1, RA2 and RO by 2050 under the emission scenario RCP4.5 and up to $6.8,3.4$ and 2,9 units, respectively in RA1, RA2 and RO, while the colour index could decrease by 2050 between 1.5 and 1.9 units in RA2 and between 1.9 and 2.4 units in RA1, respectively under the RCP4.5 under the RCP8.5 emission scenario. Nevertheless, Kizildeniz et al. (2015) indicated that elevated $\mathrm{CO} 2$, elevated temperature and drought reduced total polyphenol index (TPI) and increased colour density, but did not modify anthocyanin concentration. Thus, 
more research is still needed to reach a full understanding of how the specific phenolic compounds accumulation in the berry may be modified under changing environmental conditions.

\section{Conclusions}

The spatial and temporal variability existing at present within the Rioja DOCa, allows extracting useful information about the potential changes of vine response under future climate change scenarios. The predictions of the changes in temperature under two climate change scenarios, RCP4.5 and RCP8.5, suggest an earlier onset of all analysed phenological stages for the Tempranillo variety with biggest advances for veraison and maturity than for the earlier stage, with small differences between the warmest and the coolest zones analysed in Rioja DOCa. The increase in temperature will produce not only a shortening of the phenological timing but also a shortening of the intervals between phenological events, which is higher during ripening than in previous stages and in the warmer areas. The projected effects on grape composition, estimated from the projected changes in temperature under climate change scenarios, indicate decreasing values of total acidity in the three analysed zones. Regarding the changes in anthocyanins and TPI, the effect will depend on both increasing temperature and increasing water deficits, which will have opposite effects, but the effect may be higher in RA1 than in RA2 or in RO zone. The differences found in this research among the cooler and the warmer areas, could be considered in order to stablish strategies to mitigate the effect of climate change on grape production in this viticultural region. Athough the research was based on the information recorded in a limited number of plots in each area, the results offer a first analyse of the possibilities that the areas located at higher elevation offer to maintain grape quality under changes in climatic conditions produced by climate change.

\section{Acknowledgements}

Authors thank the Consejo Regulador of Rioja DOCa by the information related to the plots analysed in the research and the Government of La Rioja by climatic information used in this study. This research did not receive any specific grant from funding agencies in the public, commercial, or not-for-profit sectors. 


\section{References}

Allen, R.G., Pereira, L.S., Raes, D., Smith, M. 1998. Crop evapotranspiration. Guidelines for computing crop water requirements. FAO Irrigation and Drainage Paper, no. 56. FAO - Food and Agriculture Organization of the United Nations. Roma.

Ashenfelter, O., 2018. Predicting the quality and prices of bordeaux wine. World Sci. Handb. Financ. Econ. Ser. https://doi.org/10.1142/9789813232747_0002

Baillod, M., Baggiolini, M., 1993. Les stades repères de la vigne. Revue Suisse de Viticulture Arboriculture 324 Horticulture 25: 10-12.

Barnuud, N.N., Zerihun, A., Mpelasoka, F., Gibberd, M., Bates, B., 2014. Responses of grape berry anthocyanin and titratable acidity to the projected climate change across the Western Australian wine regions. Int. J. Biometeorol. 58, 1279-93. https://doi.org/10.1007/s00484-013-0724-1

Berdeja, M., Nicolas, P., Kappel, C., Dai, Z.W., Hilbert, G., Peccoux, A., Lafontaine, M., Ollat, N., Gomès, E., Delrot, S., 2015. Water limitation and rootstock genotype interact to alter grape berry metabolism through transcriptome reprogramming. Hortic. Res. 2. https://doi.org/10.1038/hortres.2015.12

Bock, A., Sparks, T., Estrella, N., Menzel, A., 2011. Changes in the phenology and composition of wine from Franconia, Germany. Clim. Res. 50, 69-81.

Bonada, M., Jeffery, D.W., Petrie, P.R., Moran, M.A., Sadras, V.O., 2015. Impact of elevated temperature and water deficit on the chemical and sensory profiles of Barossa Shiraz grapes and wines. Aust. J. Grape Wine Res. 21. https://doi.org/10.1111/ajgw.12142

Cáceres-Mella, A., Talaverano, M.I., Villalobos-González, L., Ribalta-Pizarro, C., Pastenes, C., 2017. Controlled water deficit during ripening affects proanthocyanidin synthesis, concentration and composition in Cabernet Sauvignon grape skins. Plant Physiol. Biochem. 117, 34-41. 
https://doi.org/10.1016/j.plaphy.2017.05.015

Caffarra, A., Eccel, E., 2011. Projecting the impacts of climate change on the phenology of grapevine in a mountain area. Aust. J. Grape Wine Res. 17, 52-61. https://doi.org/10.1111/j.17550238.2010.00118.x

Castellarin, S.D., Pfeiffer, A., Sivilotti, P., Degan, M., Peterlunger, E., Di Gaspero, G., 2007. Transcriptional regulation of anthocyanin biosynthesis in ripening fruits of grapevine under seasonal water deficit. Plant, Cell Environ. 30, 1381-1399. https://doi.org/10.1111/j.1365-3040.2007.01716.x

Cheng, G., He, Y.N., Yue, T.X., Wang, J., Zhang, Z.W., 2014. Effects of climatic conditions and soil properties on cabernet sauvignon berry growth and anthocyanin profiles. Molecules 19, 13683-13703. https://doi.org/10.3390/molecules190913683

Conradie W.J. , Carey V.A., Bonnardot V., Saayman D., van Schoor L. H. 2002. Effect of Different Environmental Factors on the Performance of Sauvignon blanc Grapevines in the Stellenbosch/Durbanville Districts of South Africa.I. Geology, Soil, Climate, Phenology and Grape Composition . S. Afr. J. Enol. Vitic., 23, 2, 78-91

Costantini, E.A.C., Bucelli, P., Priori, S., 2012. Quaternary landscape history determines the soil functional characters of terroir. Quat. Int. 265, 63-73.

Costantini, E.A.C., Pellegrini, S., Vignozzi, N., Barbetti, R., 2006. Micromorphological characterization and monitoring of internal drainage in soils of vineyards and olive groves in central Italy. Geoderma 131, 388-403. https://doi.org/10.1016/j.geoderma.2005.03.029

Deluc, L.G., Quilici, D.R., Decendit, A., Grimplet, J., Wheatley, M.D., Schlauch, K.A., Mérillon, J.-M., Cushman, J.C., Cramer, G.R., 2009. Water deficit alters differentially metabolic pathways affecting important flavor and quality traits in grape berries of Cabernet Sauvignon and Chardonnay. BMC Genomics 10. https://doi.org/10.1186/1471-2164-10-212

Duchêne, E., Schneider, C., 2005. Grapevine and climatic changes: A glance at the situation in Alsace. 
Agronomie 25, 93-99.

Fraga, H., García de Cortázar Atauri, I., Malheiro, A.C., Santos, J.A., 2016. Modelling climate change impacts on viticultural yield, phenology and stress conditions in Europe. Glob. Chang. Biol. 22. https://doi.org/10.1111/gcb.13382

García-Escudero, E., 2018 Chapter in the book La Rioja, its vineyards and wines. Ed. Gobierno de La Rioja, ISBN: 978-84-8125-688-8. 200 pp.

Greer, D.H., Weedon, M.M., 2013. The impact of high temperatures on Vitis vinifera cv. Semillon grapevine performance and berry ripening. Front. Plant Sci. 4, 491. https://doi.org/10.3389/fpls.2013.00491

Hochberg, U., Batushansky, A., Degu, A., Rachmilevitch, S., Fait, A., 2015. Metabolic and physiological responses of shiraz and cabernet sauvignon (Vitis vinifera L.) to near optimal temperatures of 25 and $35^{\circ}$ C. Int. J. Mol. Sci. 16, 24276-24294. https://doi.org/10.3390/ijms161024276

Jones, G. V, 2012. Climate, grapes, and wine: Structure and suitability in a changing climate. Acta Hortic. https://doi.org/10.17660/ActaHortic.2012.931.1

Jones, G. V, Storchmann, K.-H., 2001. Wine market prices and investment under uncertainty: An econometric model for Bordeaux Crus Classés. Agric. Econ. 26, 115-133. https://doi.org/10.1016/S0169-5150(00)00102-X

Kizildeniz, T., Mekni, I., Santesteban, H., Pascual, I., Morales, F., Irigoyen, J.J., 2015. Effects of climate change including elevated $\mathrm{CO} 2$ concentration, temperature and water deficit on growth, water status, and yield quality of grapevine (Vitis vinifera L.) cultivars. Agric. Water Manag. 159, 155-164. https://doi.org/10.1016/j.agwat.2015.06.015

Koufos, G., Mavromatis, T., Koundouras, S., Fyllas, N.M., Jones, G. V., 2014. Viticulture-climate relationships in Greece: the impacts of recent climate trends on harvest date variation. Int. J. Climatol. 34, 1445-1459. https://doi.org/10.1002/joc.3775 
Makra, L., Vitányi, B., Gál, A., Mika, J., Matyasovszky, I., Hirsch, T., 2009. Wine quantity and quality variations in relation to climatic factors in the Tokaj (Hungary) winegrowing region. Am. J. Enol. Vitic. $60,312-321$.

Malheiro, A.C., Campos, R., Fraga, H., Eiras-Dias, J., Silvestre, J., Santos, J.A., 2013. Winegrape phenology and temperature relationships in the Lisbon wine region, Portugal. J. Int. des Sci. la Vigne du Vin 47, 287-299.

Martinez de Toda, F., Sancha, J. C., Zheng, W., Balda, P., 2014. Leaf area reduction by trimming, a growing technique to restore the anthocyanins: sugars ratio decoupled by the warming climate. Vitis 53 (4), 189-192.Martínez de Toda, F., García, J., Balda, P., 2019. Preliminary results on forcing vine regrowth to delay ripening to a cooler period. Vitis, 58, 17-22.

Martínez de Toda, F., García, J., Balda, P. (2019) Preliminary results on forcing vine regrowth to delay ripening to a cooler period. Vitis, 58, 17-22.

Martínez de Toda, F., Ramos, M.C. 2019. Variability in grape composition and phenology of Tempranillo variety in zones located at different elevations and with differences in the climatic conditions. Vitis $58,131-139$.

Mira de Orduña, R. 2010. Climate change associated effects on grape and wine quality and production. Food Research International 43, 1844-1855.

Molitor, D., Junk, J., Evers, D., Hoffmann, L., Beyer, M., 2014. A high-resolution cumulative degree daybased model to simulate phenological development of grapevine. Am. J. Enol. Vitic. 65, 72-80. https://doi.org/10.5344/ajev.2013.13066

Mori, K., Goto-Yamamoto, N., Kitayama M. , Hashizume, K.,2007. Effect of high temperature on anthocyanin composition and transcription of flavonoid hydroxylase genes in 'Pinot noir' grapes (Vitis vinifera), The Journal of Horticultural Science and Biotechnology, 82:2, 199-206, doi: $10.1080 / 14620316.2007 .11512220$ 
Neumann, P.A., Matzarakis, A., 2014. Estimation of wine characteristics using a modified Heliothermal Index in Baden-Württemberg, SW Germany. Int. J. Biometeorol. 58, 407-15. https://doi.org/10.1007/s00484-013-0637-z

OIV, 2012. Compendium of International Methods of Analysis of Wines and Musts (2 vol.) International Organization of vine and wine. Paris, $619 \mathrm{pp}$.

Ojeda, H., Andary, C., Kraeva, E., Carbonneau, A., Deloire, A., 2002. Influence of pre- and postveraison water deficit on synthesis and concentration of skin phenolic compounds during berry growth of Vitis vinifera cv. Shiraz. Am. J. Enol. Vitic. 53, 261-267.

Ovadia, R., Oren-Shamir, M., Kaplunov, T., Zutahy, Y., Lichter, A., Lurie, S., 2013. Effects of plant growth regulators and high temperature on colour development in "Crimson Seedless" grapes. J. Hortic. Sci. Biotechnol. 88, 387-392.

Parker, A.K., De Cortázar-Atauri, I.G., Van Leeuwen, C., Chuine, I., 2011. General phenological model to characterise the timing of flowering and veraison of Vitis vinifera L. Aust. J. Grape Wine Res. 17, 206216. https://doi.org/10.1111/j.1755-0238.2011.00140.x

Petrie, P.R., Sadras, V.O., 2008. Advancement of grapevine maturity in Australia between 1993 and 2006: putative causes, magnitude of trends and viticultural consequences. Aust. J. Grape Wine Res. 14, 33-45. https://doi.org/10.1111/j.1755-0238.2008.00005.x

Pieri, P., 2010. Changement climatique et culture de la vigne: I'essentiel des impacts. In N. Brisson and F. Levrault (eds.), Changement climatique, agriculture et forêt en France: simulations d'impacts sur les principales espèces . Livre Vert CLIMATOR, ADEME, 213 - 224.

Ramos, M.C., 2017. Projection of phenology response to climate change in rainfed vineyards in north-east Spain. Agric. For. Meteorol. 247, 104-115. https://doi.org/10.1016/j.agrformet.2017.07.022

Ramos, M.C., Jones, G. V, Yuste, J., 2018. Phenology of tempranillo and cabernet-sauvignon varieties cultivated in the Ribera Del Duero DO: Observed variability and predictions under climate change 
scenarios. Oeno One 52, 31-44. https://doi.org/10.20870/oeno-one.2018.52.1.2119

Ramos, M.C., Martínez de Toda, F., 2019. Variability of Tempranillo grape composition in the Rioja DOCa (Spain) related to soil and climatic characteristics. J. Sci. Food Agric. 99, 1153-1165. https://doi.org/10.1002/jsfa.9283

Ramos M.C., Pérez-Álvarez E.P., Peregrina, F., Martínez de Toda, F. 2020. Relationships between grape composition of Tempranillo variety and available soil water and water stress in the Rioja DOCa. Scientia Horticulturae, 262 https://doi.org/10.1016/j.scienta.2019.109063

Real A.C., Borges, J., Sarsfield Cabral , J., Jones, G.V. 2015. Partitioning the grapevine growing season in the Douro Valley of Portugal: accumulated heat better than calendar dates. Int J Biometeorol (2015) 59:1045-1059, doi 10.1007/s00484-014-0918-1

Roby, G., Harbertson, J.F., Adams, D.A., Matthews, M.A., 2004. Berry size and vine water deficits as factors in winegrape composition: Anthocyanins and tannins. Aust. J. Grape Wine Res. 10, 100-107.

Ruml, M., Korać N., Vujadinović, M., Vuković, A., Ivanišević, D., 2015. Response of grapevine phenology to recent temperature change and variability in the wine-producing area of Sremski Karlovci, Serbia. J. Agric. Sci. 1-21. https://doi.org/10.1017/S0021859615000453

Sadras, V.O., Moran, M.A., 2013. Asymmetric warming effect on the yield and source: Sink ratio of fieldgrown grapevine. Agric. For. Meteorol. https://doi.org/10.1016/j.agrformet.2012.12.005

Sadras, V.O., Moran, M.A., 2012. Elevated temperature decouples anthocyanins and sugars in berries of Shiraz and Cabernet Franc. Aust. J. Grape Wine Res. 18. https://doi.org/10.1111/j.17550238.2012.00180.x

Sadras, V.O., Soar, C.J., 2009. Shiraz vines maintain yield in response to a $2-4{ }^{\circ} \mathrm{C}$ increase in maximum temperature using an open-top heating system at key phenostages. Eur. J. Agron. 31, 250-258.

Salazar Parra, C., Aguirreolea, J., Sánchez-Díaz, M., Irigoyen, J.J., Morales, F., 2010. Effects of climate 
change scenarios on Tempranillo grapevine (Vitis vinifera L.) ripening: response to a combination of elevated CO2 and temperature, and moderate drought. Plant Soil 337, 179-191. https://doi.org/10.1007/s11104-010-0514-z

Saxton K.E., Rawls, W. J. Romberger J. S., Papendick, R. I. 1986. Estimating Generalized Soil-water Characteristics from Texture. Soil Science Society of America Journal 1986 50:1031-1036Soil Sci. Soc. Am. J. 50(4), 1031-1036. doi:10.2136/sssaj1986.03615995005000040039x

Storchmann, K., 2005. English weather and Rhine wine quality: An ordered probit model. J. Wine Res. 16, 105-119. https://doi.org/10.1080/09571260500327648

Tomasi, D., Jones, G. V., Giust, M., Lovat, L., Gaiotti, F., 2011. Grapevine Phenology and Climate Change: Relationships and Trends in the Veneto Region of Italy for 1964-2009. Am. J. Enol. Vitic. 62, 329-339. https://doi.org/10.5344/ajev.2011.10108

Torres, N., Hilbert, G., Luquin, J., Goicoechea, N., Antolín, M.C., 2017. Flavonoid and amino acid profiling on Vitis vinifera L. cv Tempranillo subjected to deficit irrigation under elevated temperatures. J. Food Compos. Anal. 62, 51-62. https://doi.org/10.1016/j.jfca.2017.05.001

Tramontini, S., van Leeuwen, C., Domec, J.C., Destrac-Irvine, A., Basteau, C., Vitali, M., Mosbach-Schulz, O., Lovisolo, C., 2013. Impact of soil texture and water availability on the hydraulic control of plant and grape-berry development. Plant Soil 368, 215-230. https://doi.org/10.1007/s11104-012-1507$x$

van Leeuwen, C., Darriet, P. (2016)The Impact of Climate Change on Viticulture and Wine Quality. Journal of Wine Economics, 11, 150-167. doi:10.1017/jwe.2015.21

van Leeuwen, C., Friant, P., Choné, X., Tregoat, O., Koundouras, S., Dubourdieu, D., 2004. Influence of Climate, Soil, and Cultivar on Terroir. Am. J. Enol. Vitic. 55, 207-217.

Webb, L.B., Whetton, P.H., Barlow, E.W.R., 2011. Observed trends in winegrape maturity in Australia. Glob. Chang. Biol. 17, 2707-2719. 
Webb, L.B., Whetton, P.H., Barlow, E.W.R., 2007. Modelled impact of future climate change on the phenology of winegrapes in Australia. Aust. J. Grape Wine Res. 13, 165-175.

Webb, L.B., Whetton, P.H., Bhend, J., Darbyshire, R., Briggs, P.R., Barlow, E.W.R., 2012. Earlier wine-grape ripening driven by climatic warming and drying and management practices. Nat. Clim. Chang. 2, 259264.

Zapata, D., Salazar-Gutierrez, M., Chaves, B., Keller, M., Hoogenboom, G., 2017. Predicting key phenological stages for 17 grapevine cultivars (Vitis vinifera L.). Am. J. Enol. Vitic. 68. https://doi.org/10.5344/ajev.2016.15077

Zheng, W., García, J., Balda, P., Martínez de Toda, F., 2017a. Effects of late winter pruning at different phenological stages on vine yield components and berry composition in La Rioja, North-central Spain. Vine and Wine Open Access Journal. Oeno One. 51, 363-372.

Zheng, W., García, J., Balda, P., Martínez de Toda, F., 2017b. Effects of severe trimming after fruit set on the ripening process and the quality of grapes. Vitis, 56, 27-33.

Zheng, W.. Del Galdo, V., García, J., Balda, P., Martínez de Toda, F., 2017c. Minimal Pruning as a Tool to Delay Fruit Maturity and to Improve Berry Composition Under Climate Change. Am, J. Enol. Vitic. 68, 136-140. 
Table 1. Soil properties of the analysed plots (RA1 and RA2: zones located in Rioja Alta; RO: zone located in Rioja Oriental).

\begin{tabular}{|c|c|c|c|c|c|c|c|c|}
\hline Plot & $\begin{array}{l}\text { Elev } \\
\text { (m) }\end{array}$ & $\begin{array}{l}\text { Clay } \\
\text { (\%) }\end{array}$ & $\begin{array}{l}\text { Silt } \\
\text { (\%) }\end{array}$ & $\begin{array}{c}\text { Sand } \\
\text { (\%) }\end{array}$ & $\begin{array}{c}\text { Coarse } \\
\text { elements } \\
(\%)\end{array}$ & OM (\%) & $\begin{array}{l}\text { FC } \\
\text { (\%) }\end{array}$ & $\begin{array}{l}\text { WP } \\
\text { (\%) }\end{array}$ \\
\hline RA1-1 & 465 & 22.2 & 38.4 & 39.4 & 14.2 & 1.00 & 26.1 & 15.3 \\
\hline RA1-2 & 450 & 25.5 & 45.3 & 29.2 & 13.0 & 0.75 & 27.0 & 16.2 \\
\hline RA2-1 & 635 & 24.4 & 44.3 & 31.3 & 10.7 & 1.10 & 27.0 & 17.1 \\
\hline RA2-2 & 650 & 29.7 & 42.4 & 27.9 & 17.1 & 0.60 & 27.9 & 17.1 \\
\hline RO-1 & 367 & 21.1 & 49.6 & 29.3 & 10.3 & 1.53 & 26.1 & 15.4 \\
\hline RO-2 & 379 & 21.4 & 44.9 & 34.7 & 15.5 & 1.45 & 25.2 & 15.3 \\
\hline
\end{tabular}


Table2. Average, maximum and minimum dates at which different phenological stages were reached in each zone (RA1 and RA2: Rioja Alta; RO: Rioja Oriental)

\begin{tabular}{lllll}
\hline & & Stage $\mathbf{H}$ & Stage $\mathbf{M}$ & maturity \\
\hline RA1 & Mean & 27-may & 12-ago & 26-sep \\
& Max & 8-jun & 27-ago & 15-oct \\
& Min & 23-may & 29-jul & 6-sep \\
RA2 & Mean & 31-may & 17-ago & 4-oct \\
& Max & 14-jun & 28-ago & 21-oct \\
& Min & 27-may & 4-ago & 13-sep \\
& Mean & 21-may & 3-ago & 13-sep \\
& Max & 2-jun & 12-ago & 26-sep \\
& Min & 13-may & 23-jul & 27-ago \\
\hline
\end{tabular}


Table 3. Average, maximum and minimum values of the grape composition parameters (total acidity (AcT); malic acid (AcM), total anthocyanins (AntT); total polyphenol index (TPI), colour index (CI) reached in each zone (RA1 and RA2: Rioja Alta; RO: Rioja Oriental) at ripening $\left(P V A D=13^{\circ} \mathrm{C}\right)$

\begin{tabular}{lllllll}
\hline & & AcT & Ac M & AntT & TPI & Cl \\
\hline RA1 & Mean & 5.7 & 3.5 & 453.8 & 36.7 & 10.8 \\
& Max & 7.2 & 5.0 & 542.5 & 32.7 & 12.4 \\
& Min & 4.7 & 2.2 & 370.0 & 43.4 & 8.9 \\
& Mean & 6.7 & 4.4 & 483.4 & 32.2 & 11.7 \\
& Max & 9.1 & 5.6 & 619.5 & 38.6 & 15.9 \\
& Min & 4.7 & 3.0 & 381.5 & 25.1 & 8.0 \\
& Mean & 5.2 & 2.7 & 483.9 & 40.0 & 11.1 \\
& Max & 6.2 & 3.6 & 680.5 & 51.0 & 16.8 \\
& Min & 4.5 & 2.1 & 299.0 & 31.1 & 7.9 \\
\hline
\end{tabular}


Table 4. Average predicted changes in monthly precipitation (P) (ratio $\left.P_{\text {predicted }} / P_{\text {present }}\right)$, in maximum and minimum temperature (Tmax and $\operatorname{Tm}$ in $\left(\right.$ in ${ }^{\circ} \mathrm{C}$ ) and in solar radiation (SR) (ratio $\mathrm{P}_{\text {predicted }} / \mathrm{P}_{\text {present }}$ ) for the three analysed zones within the Rioja DOCa (RA1 and RA2: Rioja Alta; RO: Rioja Oriental).

\begin{tabular}{|c|c|c|c|c|c|c|c|c|c|c|c|c|}
\hline & J & $\mathbf{F}$ & M & A & M & J & J & A & $\mathbf{S}$ & 0 & $\mathbf{N}$ & D \\
\hline \multicolumn{13}{|c|}{ RCP4.5 2050} \\
\hline \multicolumn{13}{|l|}{ RO } \\
\hline $\mathbf{P}$ & 0.89 & 0.96 & 0.89 & 0.91 & 0.93 & 0.82 & 0.72 & 0.80 & 0.94 & 0.91 & 0.91 & 0.91 \\
\hline Tmax & 1.50 & 3.50 & 1.60 & 1.70 & 2.10 & 2.70 & 3.20 & 3.10 & 2.60 & 2.20 & 1.70 & 1.60 \\
\hline Tmin & 1.50 & 2.40 & 1.30 & 1.40 & 1.40 & 1.90 & 2.30 & 2.30 & 2.10 & 1.70 & 1.30 & 1.30 \\
\hline SR & 1.0 & 1.1 & 1.0 & 1.0 & 1.1 & 1.1 & 1.0 & 1.0 & 1.0 & 1.0 & 1.0 & 1.0 \\
\hline \multicolumn{13}{|l|}{ RA1 } \\
\hline $\mathbf{P}$ & 0.91 & 0.98 & 0.93 & 0.92 & 0.94 & 0.83 & 0.77 & 0.82 & 0.96 & 0.92 & 0.92 & 0.91 \\
\hline Tmax & 1.50 & 1.60 & 1.60 & 1.80 & 2.10 & 2.70 & 3.10 & 3.00 & 2.80 & 2.10 & 1.60 & 1.50 \\
\hline Tmin & 1.40 & 1.40 & 1.30 & 1.30 & 1.50 & 1.90 & 2.30 & 2.30 & 2.10 & 1.70 & 1.40 & 1.40 \\
\hline SR & 1.0 & 1.1 & 1.0 & 1.1 & 1.1 & 1.1 & 1.0 & 1.0 & 1.0 & 1.0 & 1.1 & 1.0 \\
\hline \multicolumn{13}{|l|}{ RA2 } \\
\hline $\mathbf{P}$ & 0.88 & 0.99 & 0.90 & 0.91 & 0.93 & 0.82 & 0.74 & 0.60 & 0.94 & 0.91 & 0.88 & 0.99 \\
\hline Tmax & 1.5 & 1.60 & 1.00 & 1.80 & 2.20 & 2.70 & 3.20 & 3.10 & 2.70 & 2.20 & 1.70 & 1.60 \\
\hline Tmin & 1.4 & 1.40 & 1.20 & 1.30 & 1.40 & 1.80 & 2.40 & 2.30 & 2.20 & 1.70 & 1.40 & 1.30 \\
\hline SR & 1.0 & 1.0 & 1.0 & 1.1 & 1.1 & 1.1 & 1.1 & 1.0 & 1.0 & 1.1 & 1.1 & 1.0 \\
\hline \multicolumn{13}{|c|}{ RCP8.5 2050} \\
\hline \multicolumn{13}{|l|}{ RO } \\
\hline $\mathbf{P}$ & 0.92 & 0.94 & 0.87 & 0.83 & 0.87 & 0.79 & 0.56 & 0.73 & 0.92 & 0.88 & 0.88 & 0.92 \\
\hline Tmax & 2.00 & 2.00 & 2.00 & 2.40 & 2.90 & 3.60 & 4.10 & 4.00 & 3.60 & 2.90 & 2.00 & 2.00 \\
\hline Tmin & 1.80 & 1.70 & 1.60 & 1.80 & 2.00 & 2.60 & 3.20 & 3.10 & 2.90 & 2.20 & 1.80 & 1.70 \\
\hline SR & 1.0 & 1.1 & 1.0 & 1.1 & 1.1 & 1.1 & 1.1 & 1.1 & 1.1 & 1.1 & 1.0 & 1.1 \\
\hline \multicolumn{13}{|l|}{ RA1 } \\
\hline $\mathbf{P}$ & 0.93 & 0.97 & 0.90 & 0.85 & 0.89 & 0.79 & 0.65 & 0.78 & 0.95 & 0.87 & 0.93 & 0.97 \\
\hline Tmax & 1.90 & 2.00 & 2.00 & 2.30 & 2.70 & 3.30 & 3.80 & 3.80 & 3.60 & 2.80 & 1.90 & 2.00 \\
\hline Tmin & 1.80 & 1.70 & 1.60 & 1.70 & 1.90 & 2.50 & 3.00 & 2.90 & 2.90 & 2.20 & 1.80 & 1.70 \\
\hline SR & 1.0 & 1.1 & 1.1 & 1.1 & 1.1 & 1.1 & 1.1 & 1.1 & 1.1 & 1.1 & 1.1 & 1.0 \\
\hline \multicolumn{13}{|l|}{ RA2 } \\
\hline $\mathbf{P}$ & 0.91 & 0.96 & 0.87 & 0.84 & 0.87 & 0.79 & 0.63 & 0.57 & 0.92 & 0.86 & 0.91 & 0.96 \\
\hline Tmax & 2.00 & 2.00 & 1.50 & 2.30 & 2.80 & 3.40 & 3.90 & 3.90 & 3.50 & 2.80 & 2.00 & 2.00 \\
\hline Tmin & 1.80 & 1.70 & 1.50 & 1.70 & 1.90 & 2.40 & 3.00 & 3.00 & 2.90 & 2.20 & 1.80 & 1.70 \\
\hline SR & 1.1 & 1.1 & 1.0 & 1.1 & 1.1 & 1.1 & 1.1 & 1.0 & 1.1 & 1.1 & 1.1 & 1.0 \\
\hline
\end{tabular}


Table 4( connt)

\begin{tabular}{|c|c|c|c|c|c|c|c|c|c|c|c|c|}
\hline & J & $\mathbf{F}$ & $M$ & A & $M$ & J & J & A & $S$ & 0 & $\mathbf{N}$ & D \\
\hline \multicolumn{13}{|c|}{ RCP4.5 2070} \\
\hline \multicolumn{13}{|c|}{ RO } \\
\hline $\mathbf{P}$ & 0.89 & 0.96 & 0.89 & 0.91 & 0.93 & 0.82 & 0.72 & 0.80 & 0.94 & 0.91 & 0.91 & 0.91 \\
\hline Tmax & 1.50 & 3.50 & 1.60 & 1.70 & 2.10 & 2.70 & 3.20 & 3.10 & 2.60 & 2.20 & 1.70 & 1.60 \\
\hline $\operatorname{Tmin}$ & 1.50 & 2.40 & 1.30 & 1.40 & 1.40 & 1.90 & 2.30 & 2.30 & 2.10 & 1.70 & 1.30 & 1.30 \\
\hline SR & 1.0 & 1.1 & 1.0 & 1.1 & 1.1 & 1.1 & 1.1 & 1.0 & 1.0 & 1.0 & 1.0 & 1.0 \\
\hline \multicolumn{13}{|l|}{ RA1 } \\
\hline $\mathbf{P}$ & 0.91 & 0.98 & 0.93 & 0.92 & 0.94 & 0.83 & 0.77 & 0.82 & 0.96 & 0.92 & 0.92 & 0.91 \\
\hline Tmax & 1.50 & 1.60 & 1.60 & 1.80 & 2.10 & 2.70 & 3.10 & 3.00 & 2.80 & 2.10 & 1.60 & 1.50 \\
\hline $\operatorname{Tmin}$ & 1.40 & 1.40 & 1.30 & 1.30 & 1.50 & 1.90 & 2.30 & 2.30 & 2.10 & 1.70 & 1.40 & 1.40 \\
\hline SR & 1.0 & 1.1 & 1.0 & 1.1 & 1.1 & 1.1 & 1.1 & 1.1 & 1.0 & 1.1 & 1.1 & 1.0 \\
\hline \multicolumn{13}{|l|}{ RA2 } \\
\hline $\mathbf{P}$ & 0.88 & 0.99 & 0.90 & 0.91 & 0.93 & 0.82 & 0.74 & 0.60 & 0.94 & 0.91 & 0.88 & 0.99 \\
\hline Tmax & 2.00 & 2.00 & 1.50 & 2.30 & 2.80 & 3.40 & 3.90 & 3.90 & 3.50 & 2.80 & 2.00 & 2.00 \\
\hline Tmin & 1.80 & 1.70 & 1.50 & 1.70 & 1.90 & 2.40 & 3.00 & 3.00 & 2.90 & 2.20 & 1.80 & 1.70 \\
\hline SR & 1.0 & 1.1 & 1.0 & 1.1 & 1.1 & 1.1 & 1.1 & 1.1 & 1.0 & 1.1 & 1.1 & 1.0 \\
\hline \multicolumn{13}{|c|}{ RCP8.5 2070} \\
\hline \multicolumn{13}{|l|}{ RO } \\
\hline $\mathbf{P}$ & 0.92 & 0.94 & 0.87 & 0.83 & 0.87 & 0.79 & 0.56 & 0.73 & 0.92 & 0.88 & 0.88 & 0.92 \\
\hline Tmax & 2.00 & 2.00 & 2.00 & 2.40 & 2.90 & 3.60 & 4.10 & 4.00 & 3.60 & 2.90 & 2.00 & 2.00 \\
\hline $\operatorname{Tmin}$ & 1.80 & 1.70 & 1.60 & 1.80 & 2.00 & 2.60 & 3.20 & 3.10 & 2.90 & 2.20 & 1.80 & 1.70 \\
\hline SR & 1.0 & 1.1 & 1.0 & 1.1 & 1.1 & 1.1 & 1.1 & 1.0 & 1.0 & 1.0 & 1.0 & 1.0 \\
\hline \multicolumn{13}{|l|}{ RA1 } \\
\hline $\mathbf{P}$ & 0.93 & 0.97 & 0.90 & 0.85 & 0.89 & 0.79 & 0.65 & 0.78 & 0.95 & 0.87 & 0.93 & 0.97 \\
\hline Tmax & 1.90 & 2.00 & 2.00 & 2.30 & 2.70 & 3.30 & 3.80 & 3.80 & 3.60 & 2.80 & 1.90 & 2.00 \\
\hline Tmin & 1.80 & 1.70 & 1.60 & 1.70 & 1.90 & 2.50 & 3.00 & 2.90 & 2.90 & 2.20 & 1.80 & 1.70 \\
\hline SR & 1.0 & 1.1 & 1.0 & 1.1 & 1.1 & 1.0 & 1.0 & 1.0 & 1.0 & 1.0 & 1.0 & 1.0 \\
\hline \multicolumn{13}{|l|}{ RA2 } \\
\hline $\mathbf{P}$ & 0.91 & 0.96 & 0.87 & 0.84 & 0.87 & 0.79 & 0.63 & 0.57 & 0.92 & 0.86 & 0.91 & 0.96 \\
\hline Tmax & 2 & 2.1 & 2 & 2.3 & 2.9 & 3.7 & 4.3 & 4.3 & 3.8 & 3 & 2.4 & 2.1 \\
\hline Tmin & 1.7 & 1.6 & 1.6 & 1.6 & 2 & 2.6 & 3.4 & 3.3 & 3.1 & 2.4 & 1.9 & 1.9 \\
\hline SR & 1.1 & 1.1 & 1.1 & 1.1 & 1.1 & 1.1 & 1.1 & 1.1 & 1.1 & 1.1 & 1.1 & 1.1 \\
\hline
\end{tabular}


Table 5. Projected changes in water deficits in the periods between stages (budbreak (BB) to stage $\mathrm{H}$, stage $\mathrm{H}$-stage $\mathrm{M}$ and stage $\mathrm{M}$-maturity) for the three zones (RA1 and RA2: Rioja Alta; RO: Rioja Oriental) under the RCP4.5 and RCP8.5 emission scenarios, by 2050 and 2070 (based on the average projected changes in temperature and precipitation simulated with an ensemble of models).

\begin{tabular}{|c|c|c|c|c|c|}
\hline \multirow{2}{*}{\multicolumn{2}{|c|}{$\begin{array}{l}\text { Emission } \\
\text { scenario }\end{array}$}} & \multirow{3}{*}{$\begin{array}{l}\text { time } \\
2050\end{array}$} & \multicolumn{3}{|c|}{ Changes in P-ETc $(\mathrm{mm})$} \\
\hline & & & \multirow{2}{*}{$\begin{array}{c}\text { BB-stage } \mathbf{H} \\
-75\end{array}$} & \multirow{2}{*}{$\begin{array}{c}\text { stage } \mathbf{H} \text {-stage } \mathbf{M} \\
-112\end{array}$} & \multirow{2}{*}{$\begin{array}{c}\text { stage M-maturity } \\
-108\end{array}$} \\
\hline RA1 & RCP4.5 & & & & \\
\hline & & 2070 & -105 & -141 & -127 \\
\hline & RCP8.5 & 2050 & -102 & -144 & -135 \\
\hline & & 2070 & -112 & -162 & -177 \\
\hline \multirow[t]{4}{*}{ RA2 } & RCP4.5 & 2050 & -32 & -98 & -106 \\
\hline & & 2070 & -55 & -121 & -119 \\
\hline & RCP8.5 & 2050 & -39 & -112 & -110 \\
\hline & & 2070 & -63 & -134 & -151 \\
\hline \multirow[t]{4}{*}{ RO } & RCP4.5 & 2050 & -29 & -57 & -68 \\
\hline & & 2070 & -29 & -58 & -69 \\
\hline & RCP8.5 & 2050 & -45 & -80 & -93 \\
\hline & & 2070 & -42 & -77 & -89 \\
\hline
\end{tabular}


Table 6 Projected advances (in days) of the stage $\mathrm{H}$ (separated flowers), the stage M (veraison) and maturity and projected shortening of the periods between stages (stage $\mathrm{H}$-stage $\mathrm{M}$ and stage M-maturity) for the three zones (RA1 and RA2: Rioja Alta; RO: Rioja Oriental) under the RCP4.5 and RCP8.5 emission scenarios by 2050 and 2070 (based on the average thermal requirements ( GDD) using the average projected temperature simulated with an ensemble of models).

\begin{tabular}{|c|c|c|c|c|c|c|c|}
\hline & \multirow[t]{3}{*}{$\begin{array}{l}\text { Emission } \\
\text { scenario }\end{array}$} & \multirow[t]{3}{*}{ time } & \multicolumn{3}{|c|}{$\begin{array}{l}\text { Advance of the phenological events } \\
\qquad \text { (days) }\end{array}$} & \multicolumn{2}{|c|}{$\begin{array}{l}\text { Shortening of the periods } \\
\text { (days) }\end{array}$} \\
\hline & & & stage & stage & stage & Period & Period \\
\hline & & & $\mathbf{H}$ & M & Maturity & H-M & M-Maturity \\
\hline \multirow[t]{4}{*}{ RA1 } & RCP4.5 & 2050 & 3 & 5 & 9 & 2 & 4 \\
\hline & & 2070 & 5 & 8 & 12 & 2 & 4 \\
\hline & RCP8.5 & 2050 & 7 & 10 & 14 & 3 & 4 \\
\hline & & 2070 & 10 & 16 & 20 & 5 & 4 \\
\hline \multirow[t]{4}{*}{ RA2 } & RCP4.5 & 2050 & 5 & 6 & 12 & 1 & 4 \\
\hline & & 2070 & 7 & 8 & 14 & 1 & 4 \\
\hline & RCP8.5 & 2050 & 8 & 11 & 15 & 2 & 4 \\
\hline & & 2070 & 12 & 16 & 21 & 3 & 5 \\
\hline \multirow[t]{4}{*}{ RO } & RCP4.5 & 2050 & 5 & 8 & 10 & 3 & 2 \\
\hline & & 2070 & 9 & 10 & 12 & 3 & 3 \\
\hline & RCP8.5 & 2050 & 8 & 12 & 15 & 4 & 3 \\
\hline & & 2070 & 12 & 17 & 22 & 5 & 6 \\
\hline
\end{tabular}


Table 7. Predicted changes in grape composition in the three analysed zones of Rioja DOCa based on temperature and precipitation changes.

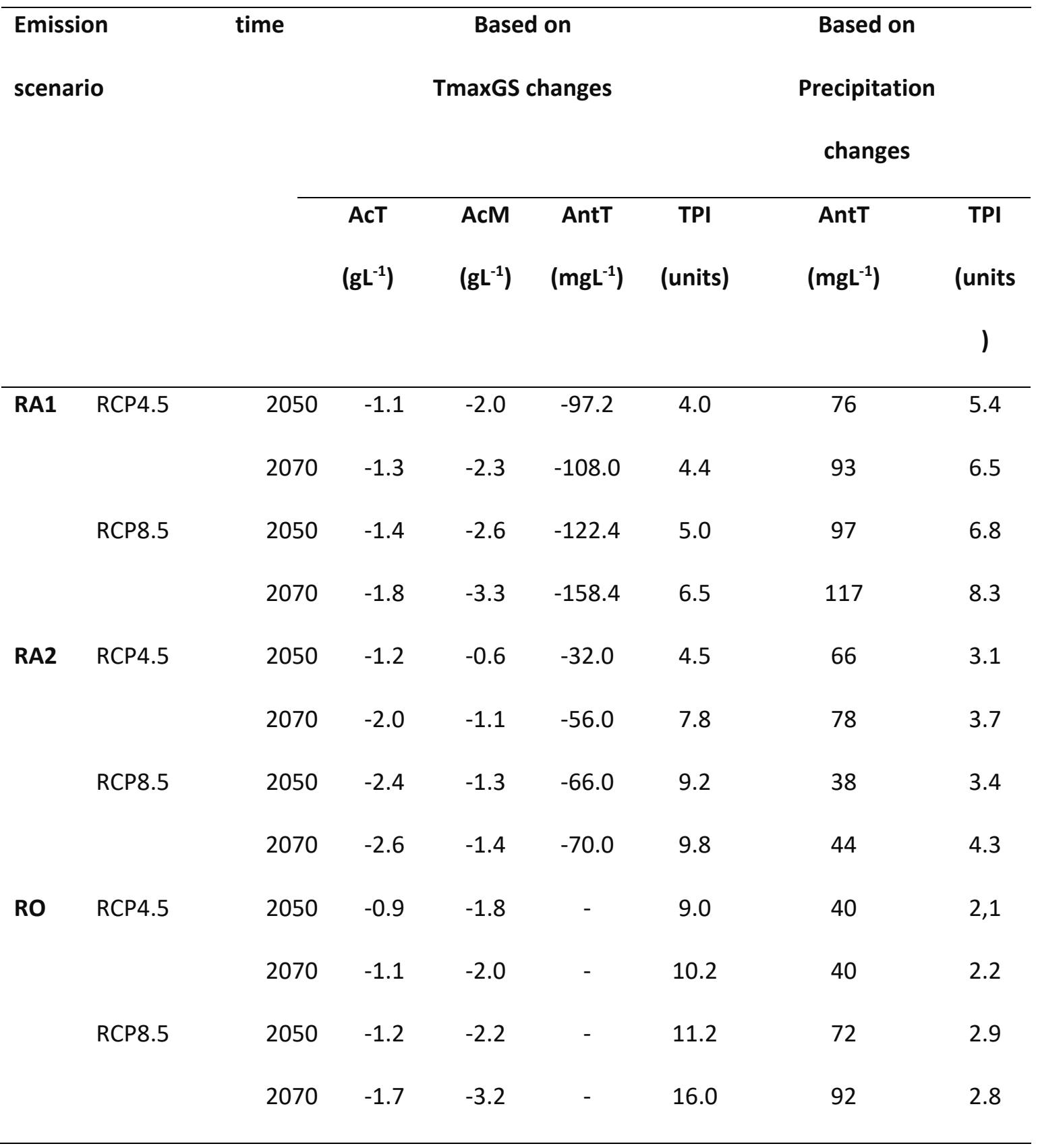




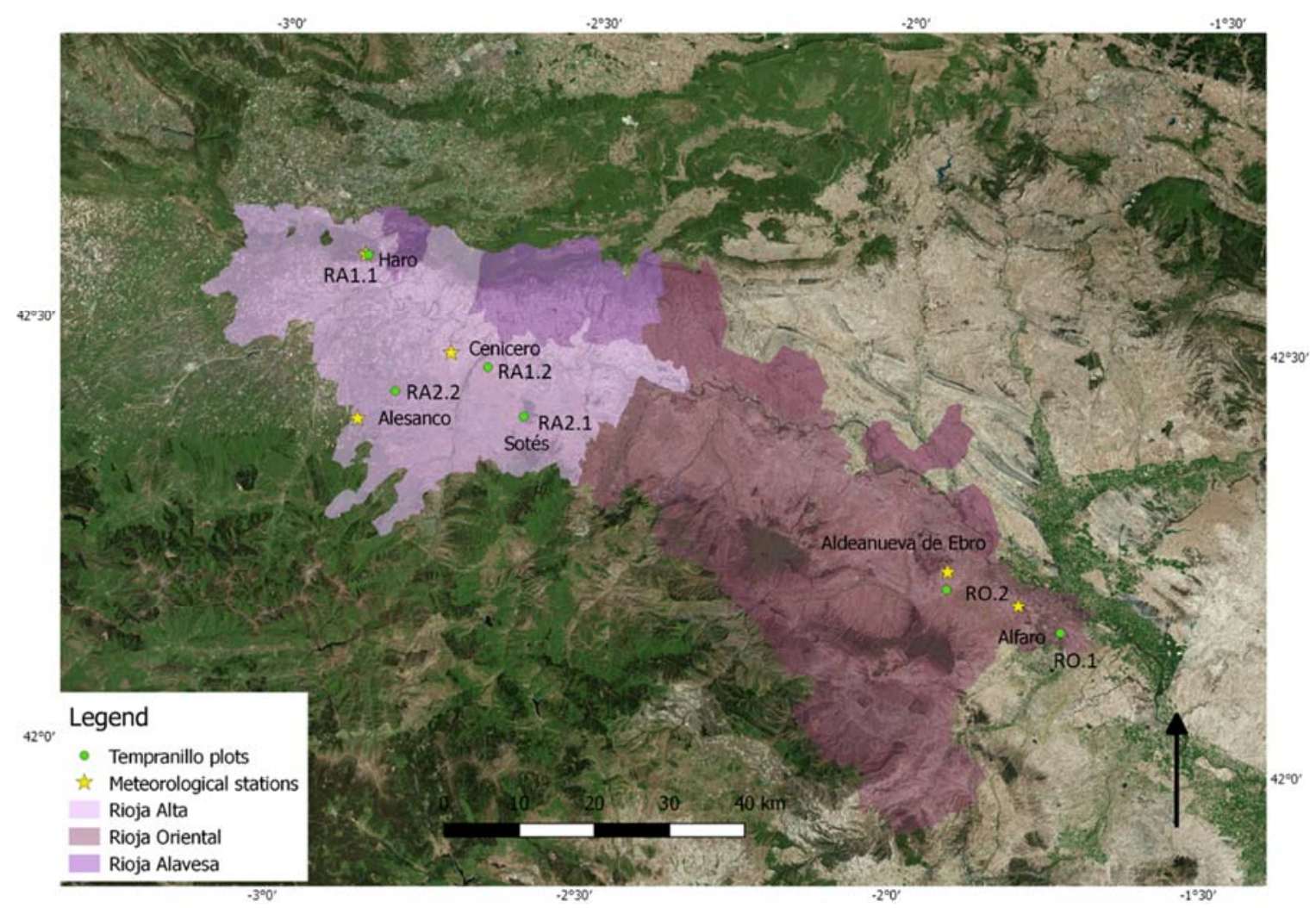

Fig.1 Location of the plots and meterological stations used in this research. 

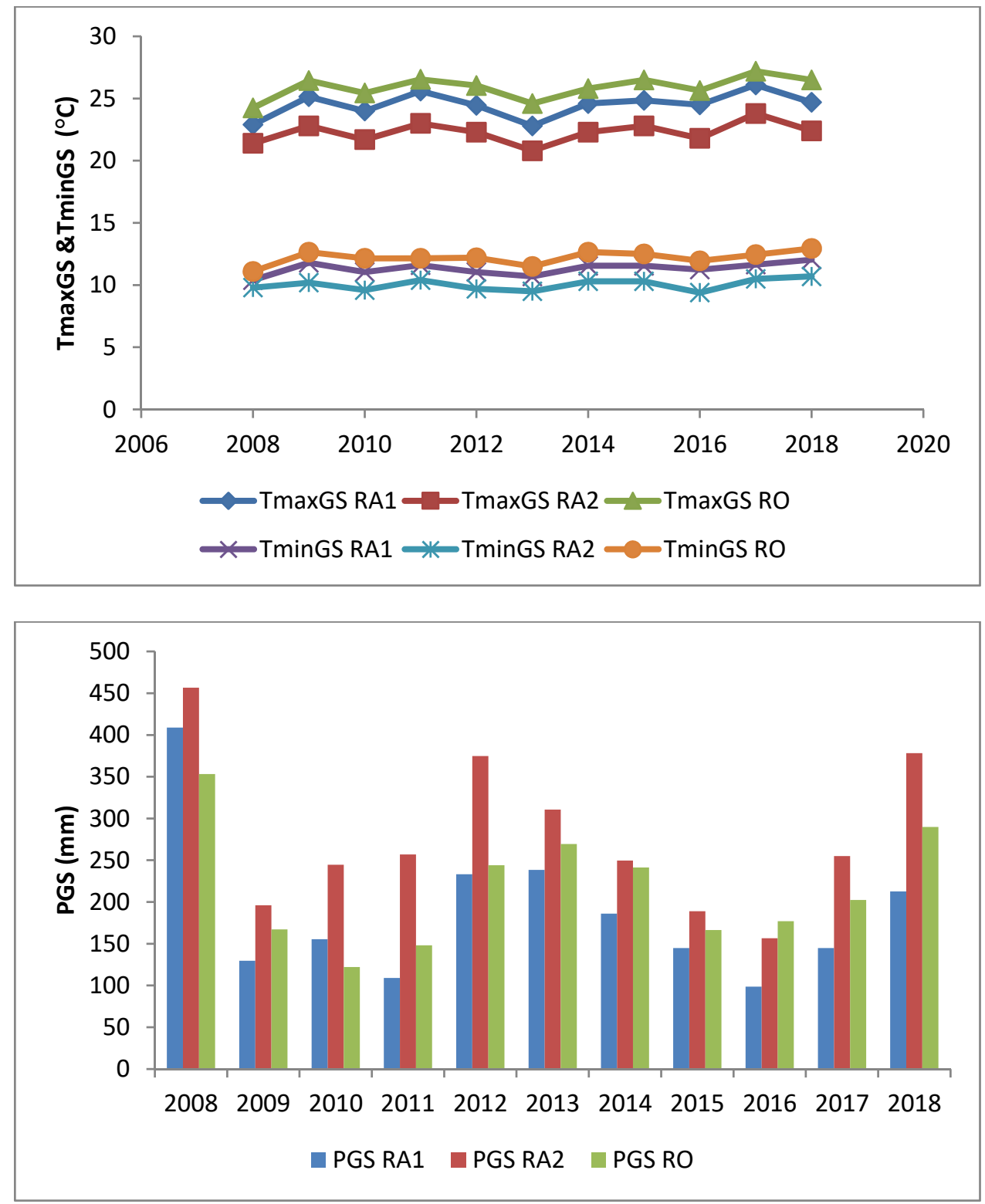

Fig. 2. Average maximum and minimum temperatures (TmaxGS and TminGS) and precipitation (PGS) referred to the growing season, recorded during the period of analysis (2008-2018) in the three analysed zones (RA1 and RA2: Rioja Alta; RO: Rioja Oriental). 
